TENTATIVE DESIGN GUIDE

FOR

CALCULATING THE VIBRATION RESPONSE

OF FLEXIBLE GYLINDRICAL ELEMENTS IN

AXIAL FLOW

by

M. H. WambBganss

and

S. S. Chen

Englneering and Technology Ditision

Argonne National Laboratory

Argonne, Illinola

Apr11, 2971

This neort we prepered as en nceount of work epomecred by the United gutes Gownanent. Nether the United Statew nor the United states Atonic Eandy

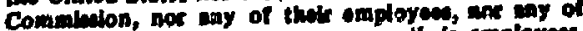

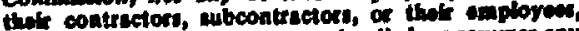

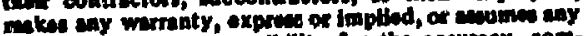

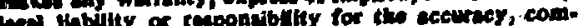
cht

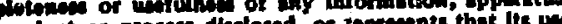

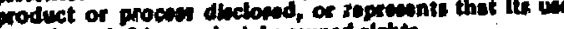




\section{TABLE OF CONTBNSS}

Page

NOMENCLATURE

4

$\begin{array}{ll}\text { ABSTRACT } & 7\end{array}$

I. INTRODUCTION

II. RYS DISPLACEAENT RESPONSE

A. Equation of Motion 10

B. Parameter Study $\quad 11$

C. Fundameatal Vibration Frequency 15

D. Flow-Velocity-Dependent Damplng 16

E. Flow-Noise Excitation 16

B. Summary 19

III. AMPLITUDE DISTRIBUTION 20

IV. EXAMPLE OR APPLICATION 22

จ. DISCUSSION 25

$\begin{array}{ll}\text { REPERENCES } & 26\end{array}$ 


\section{LIST OF FIGURES}

No.

Iitle

Page

1

Rlextble cylinder in axial flow and coordinate gystem

2 Added mass coefficient $\left(C_{m}\right)$ ss a function of diameter
ratio $(D / d)$

9

3

Bffective diameter $(x)$ as a function of $v$

4

Joint acceptance of the fundamental mode as $a$ function of $\gamma$

Tamily of near-field mean-square spectra as a function of $S$

Equivalent viscous damping factor $\left(\zeta_{1}\right)$ as a function of meen axial flow velocity (U) for a $0.5-1 n .-d i a$, 46-7/8 -In.-1ong brass rod with fixed-fixed ends

Typical probability denstty repreaentation of displacement of flexible cylinder vibrating in parallel-flowing fluid $(\sigma=\operatorname{ms}$ value $=2.34 \mathrm{m1ls} ; \mathrm{U}=16 \mathrm{ft} / \mathrm{sec}$ ) 


\section{NOMENCLATURE}

Symbol

\section{Description}

a

Cylinder radius, In.

$a_{1} \quad$ Empirical constant, sec/ft

$a_{2} \quad$ Enpixical constant, $\sec ^{2} / \mathrm{ft}^{2}$

b Axial location, in.

$c_{T} \quad$ Tangential drag coefficient

d Cylinder, diameter, in.

i h Hydraulic diameter, ft

d Tube Inside diameter, In.

f Frequency, Hz

fo Pundamental vibration frequency of cylinder in static flutd, Ha

$f_{1} \quad$ Fundamental vibration frequency of cylinder, $\mathrm{Hz}$

\& Cylinder length, In.

m

Cylinder mass per unit length, (1b) $\left(\sec ^{2}\right) / f t^{2}$

p

Randon pressure on cylinder aurface, $1 \mathrm{~b} / 1 \mathrm{n} .{ }^{2}$

$\mathbf{r}$

Resultant transverse diaplacement, In.

$t \quad$ TIme, sec

v Transverse displacement, in.

x. Axial coordinate, In.

$y$

Transvarse displacement, in.

$y_{\operatorname{mos}}$

C.m

Root mean square tranoverse displacement, in.

Added mase coefficlent

D

Inside diametex of annuilar flow channel, in.

B

Young's modulua of elastictey for cylinder material, $1 \mathrm{~b} / \mathrm{In} .^{2}$

H

Prequency responee (tranafer) function for cylinder

$\mathbf{I}$

Aren moment of Inortia, in. 4 
Srabol

Deecription

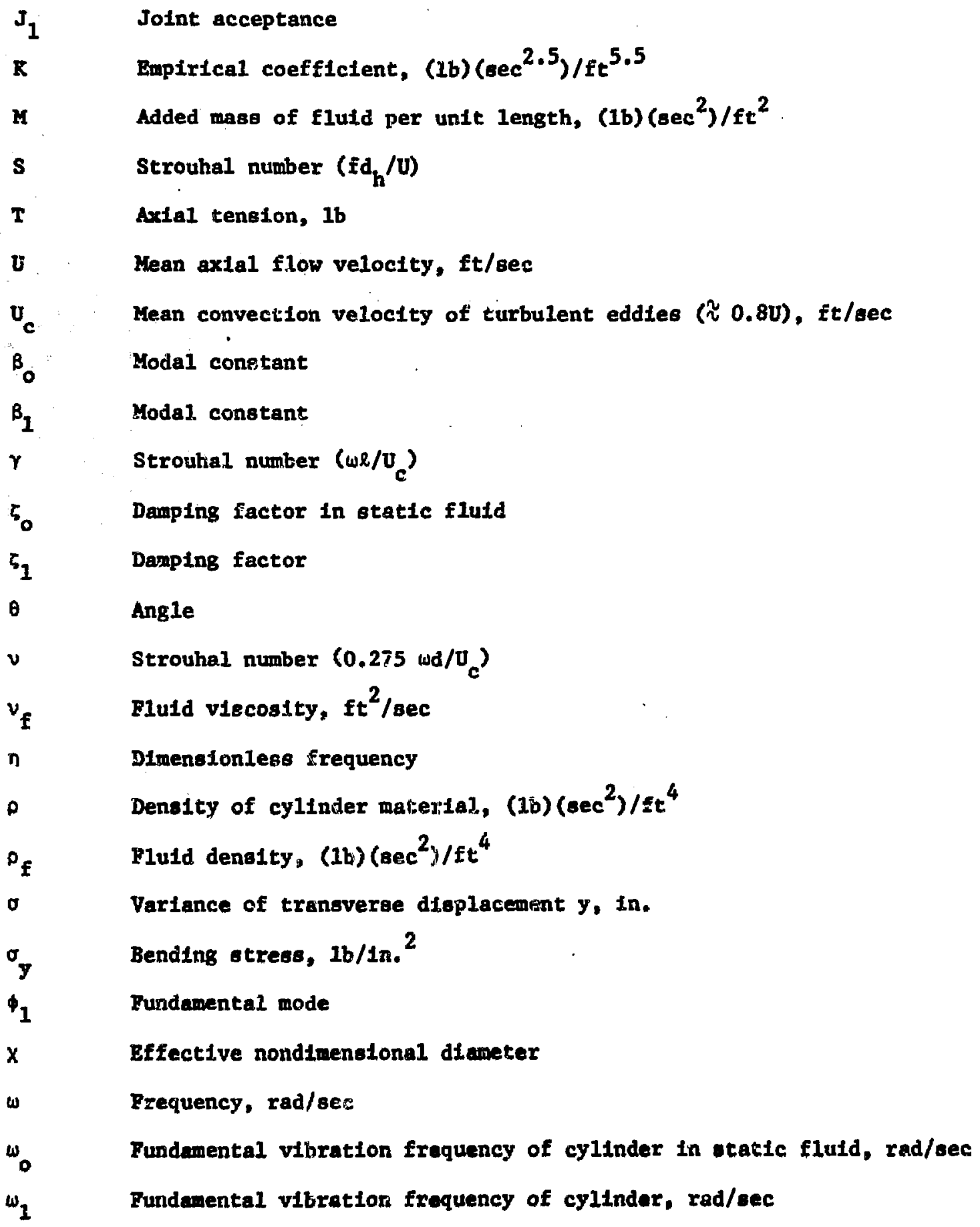


Symbol

Description

\$o Intensity of near-fleld mean-square spectral density in 1ow-frequeacy range, $\left(1 b^{2}\right)($ eec $) / 1$ n. 4

$\Phi_{p} \quad$ Mean-square spectral density of near-fleld flow noise. $\left(1 b^{2}\right)(\mathrm{sec}) / 1 \mathrm{n} .4$

I Mean-square spectra1 density of cylinder dieplacement, (1n.2) (sec) 


\title{
TEATATIVE DESIGN GUIDE \\ FOR \\ CALCULATING THE VIBRATION RESPONSE \\ OF FLEXIBLE CYLINDRICAL ELEMENTS IN \\ AXIAL FLOW
}

by

M. W. Wambsganss and S. S. Chen

\begin{abstract}
Many reactor and plant equipment components, such as fuel pins, control rods, and heat exchanger tubes, are long, slender, beam-1ike members which are exposed to nominally axlal coolant flow. The flowing coolant represents a source of energy which can induce vibratory motion of these components. This design guide presents a relationship for calculating the root-meanBquare (rms) diaplacement of a flextble rod or tube in axial flow. The relationship 18 based on the results of a parameter study and is vaitd for components that can be approximated as beans with either simpiy-aupported or fixed-fixed ends. It is given In terms of beam natural frequency, damping factor, and Intensity of the mean-aquare opectral density of the pressure fleld in the low-frequency range; all three are functions of mean axial flow velocity. Bupirical expressions are developed for damping factor and intensity of the mean-square pressure spectrum. With these, an empirical equation for rms displacement is written which is in terms of known quantities and, therefore, provides a tool which can be ased by designers. Since the equation is based on experiments involving a smooth rod in flow with minimal entrance effects, the predicted displacements should be interpreted and used with care. They are not conservative and, at best, will represent the minimum response to be expected.
\end{abstract}

\section{INTRODUCTION}

Many reactor and plant equipmeat components, such as fuel pins, control rode, and heat exchanger tubes, are leng, slender, beam-1ike members which axe exposed to noulnally axial coolant flow. The flowing coolant represents a source of energy which can induce vibratory motion of these components. Experiments have 1dentifled the displacement respoxse of these couponents as a problem in random vitration $\left[e_{.8}, 1\right]$. The resulting motion 18 forced, the near-field cosponent of the flow nolse (e.g., the random pressure fluctuations generated by turbulent eddies in the flow) betng the primary excitation mechaniom. Analysis has shown [2] that instabilitites caused by fluid-structure coupling are not a problem: for typlcal reactor syatem geometries and coolant flow anvironments, the critical flow velocities acsoclated with the onset of Instabilicy are large relative to expected velocitlles. 
Several empirical relationships for component displacement have been proposed [3-5], none of which satisfactorily predicts displacement response for all conditions. One reason is the strong systen dependence of the response; turbulence levels, as effected by entrance conditions and flow channel geonetries, are important.

This design gulde presents a theoreticaliy derived relationship for calculating the root-mean-square (rms) displacement of a flexible rod or tube In nominally exial flow. The basic analysis assumes a pressure field which is homogeneous in space; that is, the mean-square spectral density of the pressure Is the same at any point on the rod. The relationship 18 based on the results of a parameter study; it is valid for component/systems which have parameters in spectifed ranges and which can be approximated as beams with elther simplysupported or fixed-fixed ends. The relationship is given in terms of rod natural frequency, damping factor, and intensity of the near-field spectrum in the low-frequency range. All three are functions of mean axial flow velocity.

The flow velocity dependence of damping and Intensity of the near-field spectrum are not very well understood. This precludes direct application of the theoretical equation. However, these features are being studied at Argoine and preliminary experiments teni to verify the derived equation for rms response. Based on this favorable agreement, the equation was solved for the intensity of the near-field mean-square spectrum, and experimental measurements of rms displacement and damping were used to develop an empirical relationship for the flow-velocity-dependence of the Intensity of the near-field spectrim. With this relationship, and en empirical expression for the flow-velocity-dependent damping, an equation for rms displacement as a function of mean axial flow velocity and system parameters was obtained.

The equation is in terms of known quantities and, therefore, provides a tool whtch can be used by designermanalysts to predict zms displacements of flextble rods in annular water flow. However, since the equation 18 based on experiments involving a smooth rod in flow with minimal entrance effects, the predicted dioplacements should be interpreted and used with care. They are not conservative and, at best, w111 represent the minimum .esponse to be expected.

This design guide will be updated as results from the studies of damping and flow-excitation continue to become available.

\section{RMS DISPLACEREMT}

A flexible cylinder in axial flow and coordinate syatem is shown scheratically in Fig. 1. Since the problem io one of rundon vibration, the quantities of Interest are the rms value of the response and the ampiltude dietribution. The motion of the cylinder is two-dimensional because it is equally likely to respond in any direction. We will consider motion in the $y-$ direction as defined in Fig. 1.

Mean-8quare displacement is readily obtaine from the mean-6quare spectral density of the dioplacement by integration over the frequency: 

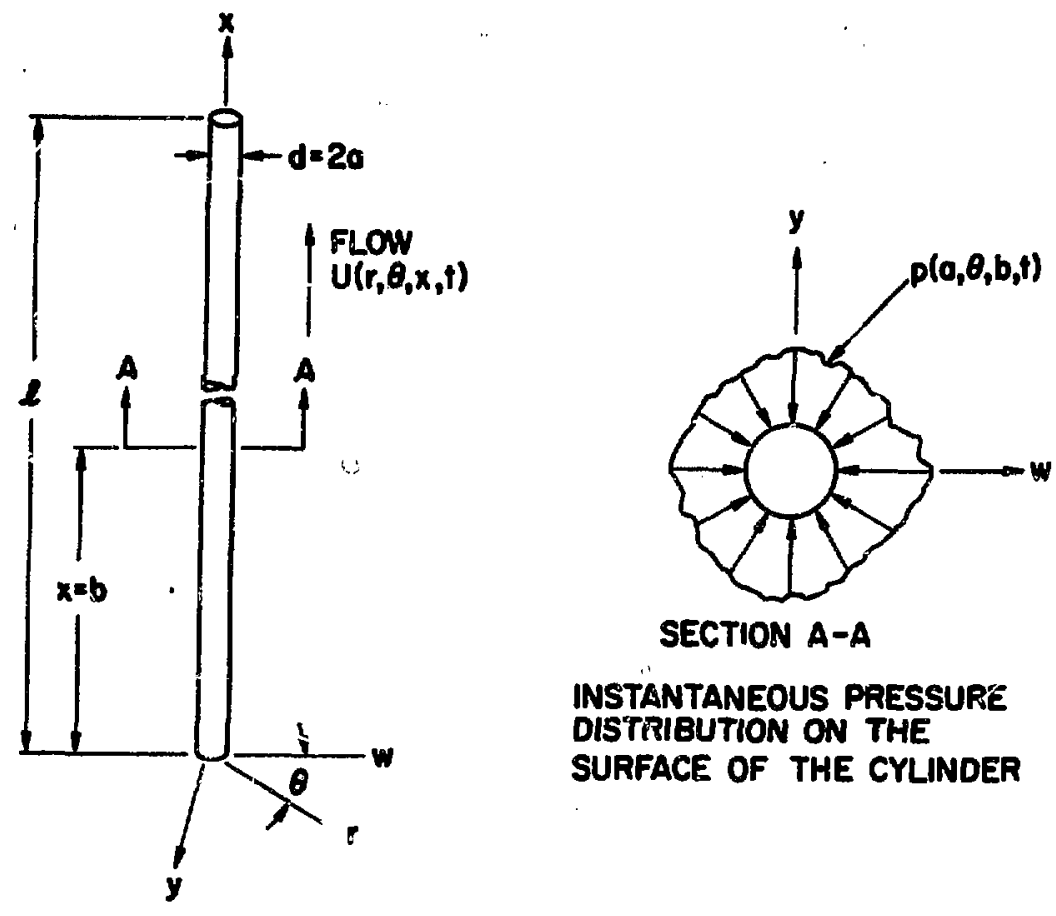

SECTION A-A

INSTANTANEOUS PRESSURE

DISTRIBUTION ON THE

SURFACE OF THE CYLINDER

Fig. 1. Flexible cylinder rod in axial flow and coordinate system

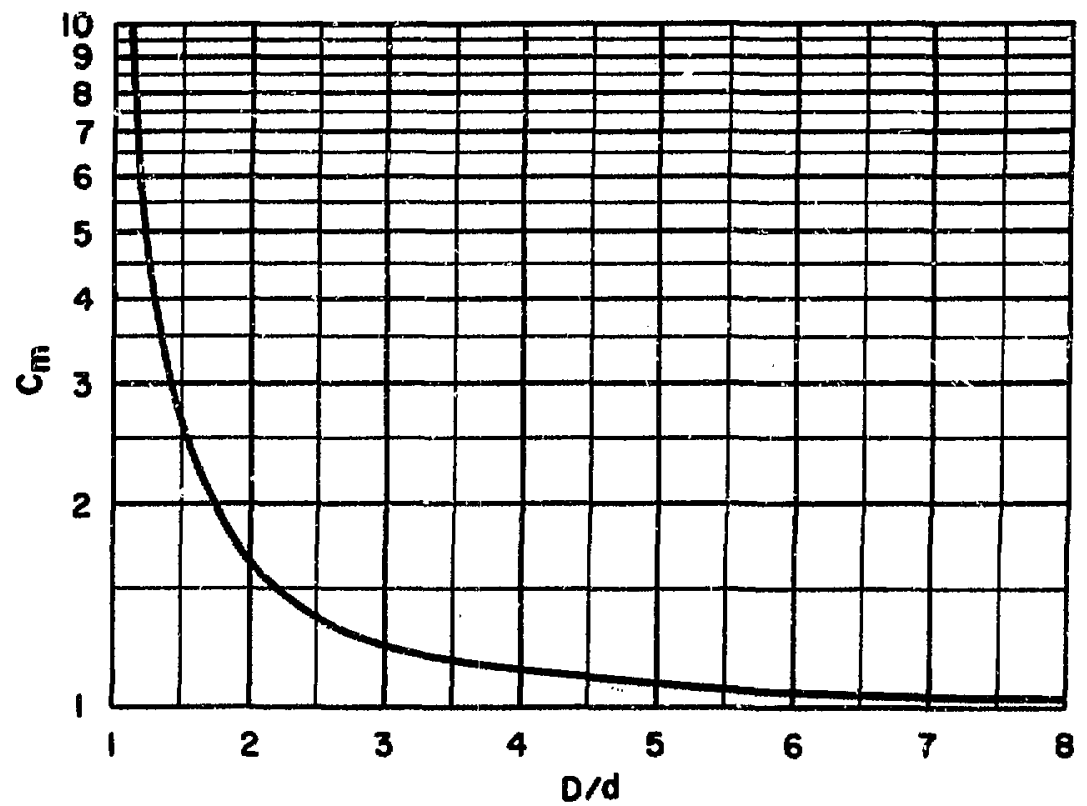

Fig. 2. Added mass coefficient $\left(C_{m}\right)$ as a function of diameter ratio $(D / A)$ 


$$
\left\langle y^{2}(x, t)\right\rangle=\int_{0}^{\infty} \Phi_{y}(x, \omega) d \omega
$$

since mean-square spectral density is simply the frequency distribution of the mean-squaze: the symbol < > denotes a time average. On the assumption that the Integration Implied in Eq. (I) can be performed, prediction of the rmsresponse then requires matherratical characterization of the mean-square apectral density of the displacement.

\section{A. Equation of Motion}

The equation for small lateral motion of a flexible rod in axial flow was formulated by Paidoussis [6]. Damping and a distributed random pressure loading were Included in a subsequent analysis [7], where the response was represented in sertes form as a superposition of normal modes, yielding a serias representation of the mean-square spectral density of the displacement. Theory [7] and experiment [1] have shown that less than $5 \%$ of the energy is contained in other than the fundamental mode; therefore, a one-mode approximation is sufficient.

We w1ll further assume that the convecting random pressure field is homogeneous in space; that is, its mean-square spectral density is the same at every point on the surface of the cylincer. Using a phenomenological model proposed by Corcos [8], and the best features of the existing data describing the convection and correlation decay of turbulent boundary-layer pressure fluctuations, the mean-square spectral density of the displacement can be written as [7]

$$
\Phi_{y}(x, \omega)=x^{2}(\omega) J_{1}^{2}(\omega) \Phi_{p}(\omega)|H(x, \omega)|^{2} \phi_{1}^{2}(x)
$$

The first term in the product on the right side is described as dimensionless "effective diameter;" It embodies the decay of the circumferential correlation of the presgure fleld. The second term, called the "Joint acceptance," Is a welghted cross-spectral density of the convecting pressure fleld; it represents the "effectiveness" :- the pressure in exciting a mode of the rod. The third term 18 the mean-square spestral density of the pressure field measured at a point. The fourth term 18 the frequency response function (transfer function) for the cylinder and is given by

$$
|H(x, \omega)|=[d /(M+m)]\left[\left(\omega_{1}^{2}-\omega^{2}\right)^{2}+4 \zeta_{1}^{2} \omega_{1}^{2} \omega^{2}\right]^{-1 / 2} .
$$

The last term is the fundamental mode; for flxed-fixed ends, It can be approximated by the classic nozmal mode

$$
\begin{aligned}
\Phi_{1}(x) & =\cosh (4.73 x / \ell)-\cos (4.73 x / 1)-0.983[\sinh (4.73 x / \ell) \\
& -\sin (4.73 x / \ell)] ;
\end{aligned}
$$

and for simply-supported ends, it is given by 


$$
\phi_{1}(x)=\sqrt{2} \sin (\pi x / \ell) .
$$

The added mass of fluld (M In Eq. (3)) Is generally assumed to be equal to the mass of fluld displaced by the cylinder; this is valid for a cylinder subeerged in an "Infinite" fluld. However, for a cylinder vibrating within a bundle, or in close proximity to a wall, boundary effects are important as they Influence the added mass. A theoretical analysis of a cylinder vibrating In a compressible flujd annulus has been performed [9]. The results are expressed in the form

$$
M=C_{m} p_{f}\left(\pi d^{2} / 4\right) \text {, }
$$

where $C_{n}$ is the added mass coefficient given in Fig. 2.

Substitution of Eq. (2) into Eq. (1) yields

$$
\left\langle y^{2}(x, t)\right\rangle=\phi_{1}^{2}(x) \int_{0}^{\infty} x^{2}(\omega) \mathrm{J}_{1}^{2}(\omega) \phi_{p}(\omega)|H(x, \omega)|^{2} d \omega
$$

Using the phenonenological model of Corcos [B] and experimental results presented in the 1iterature, the functions $x(\omega)$ and $J_{1}^{2}(\omega)$ were obtained by integration [7]. They are plotted as functions of the Strouhal numbers $v\left(=0.275 \omega d / U_{c}\right)$ and $\gamma\left(-\omega l / U_{c}\right)$ In Figs. 3 and 4 respectively. In Fig. 4 , $J_{1}^{2}(\gamma)$ is plotted for fixed-fixed and simply-supported ends.

Hean square spectral densities of the near-field flow noise have been masured, using a method In which the low-frequency acoustic noise is nulled out in the pressure differencing [10]. Representative results [11] are reproduced In Fig. 5, where the frequency has been scaled with the Strouhal nuber $S\left(-\mathrm{fd}_{\mathrm{h}} / \mathrm{U}\right)$.

Prediction of rms displacenent response requires mathematical characterization of $x_{0} J_{1}$, and $\Phi_{p}$; substitution of these quantities into Eq. (6); and Integration over the frequency. Although the Integration is not particularly difficult to perform on a computer, it will be shown that from the results of a paraweter study a siaplified relationship can be developed for rms response of typical reactor components and fluid environments.

\section{B. Parameter Study}

Three different Strouhal number relationships have been utilized in the normulization of the mean-8quare spectra, and In representation of the effective dimeter and joint acceptance associated with the random pressure field; they are respectively

and

$$
\left.\begin{array}{l}
s=f d_{h} / v, \\
v=0.275 \omega d / U_{c} \\
v \approx \omega \ell / v_{c} .
\end{array}\right\}
$$




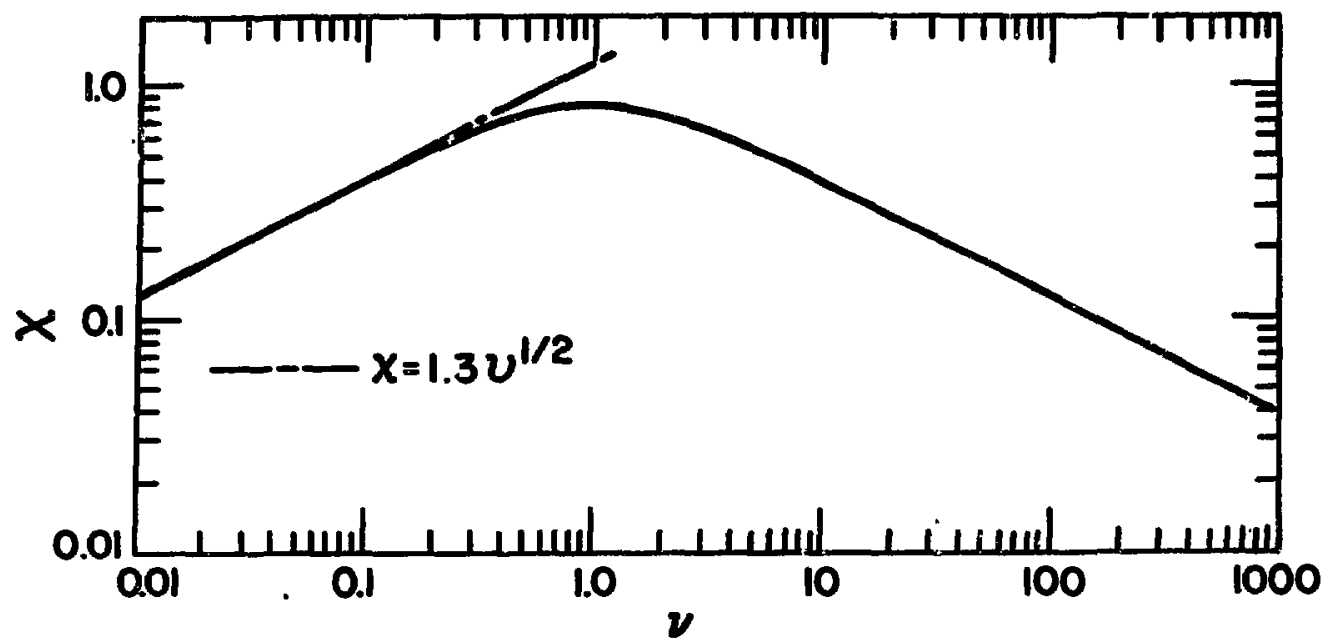

Fig. 3. Effective diameter $(x)$ as a function of $v$

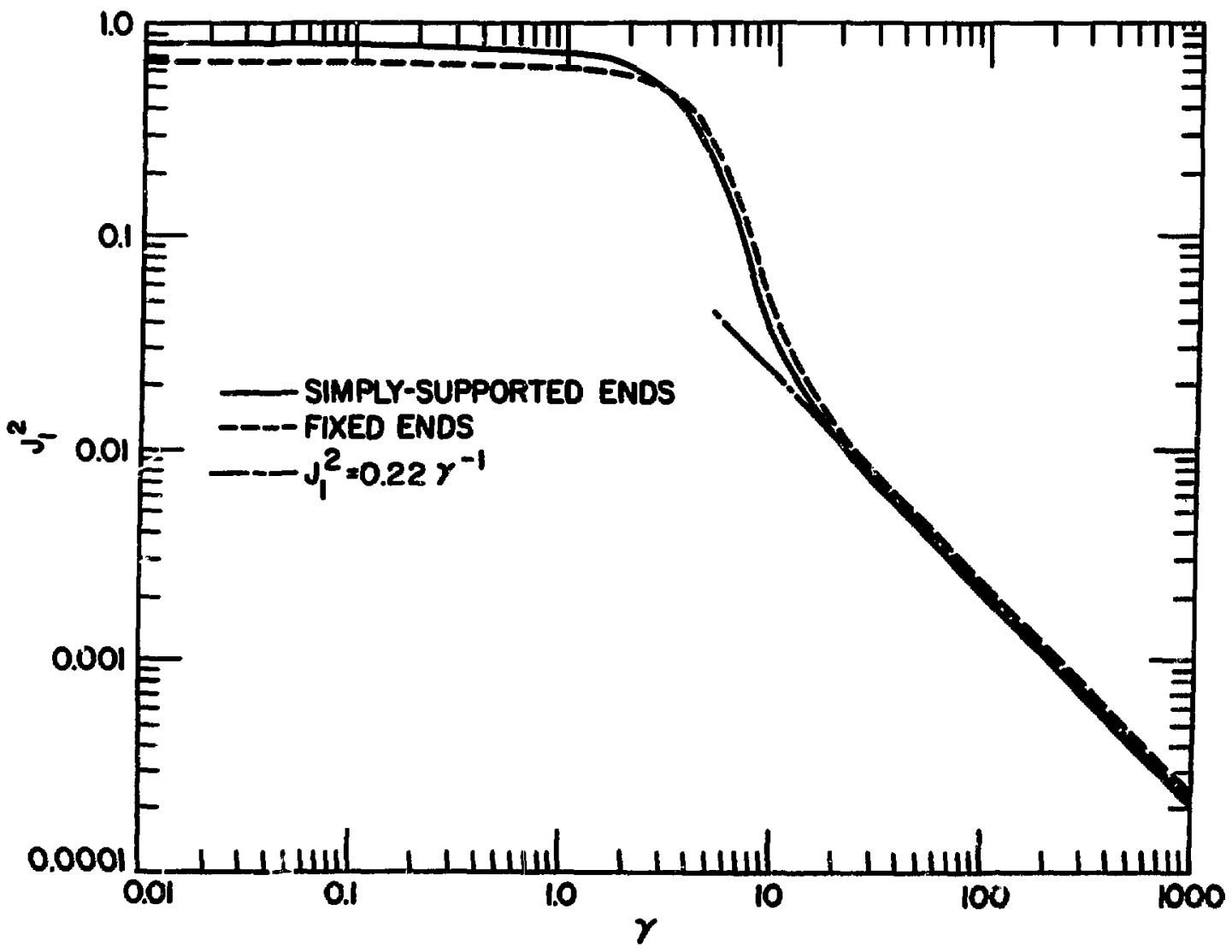

Fig. 4. Joint acceptance $\left(\mathrm{J}_{1}^{2}\right)$ of the fundamental mode as a function of $\mathrm{\gamma}$ 


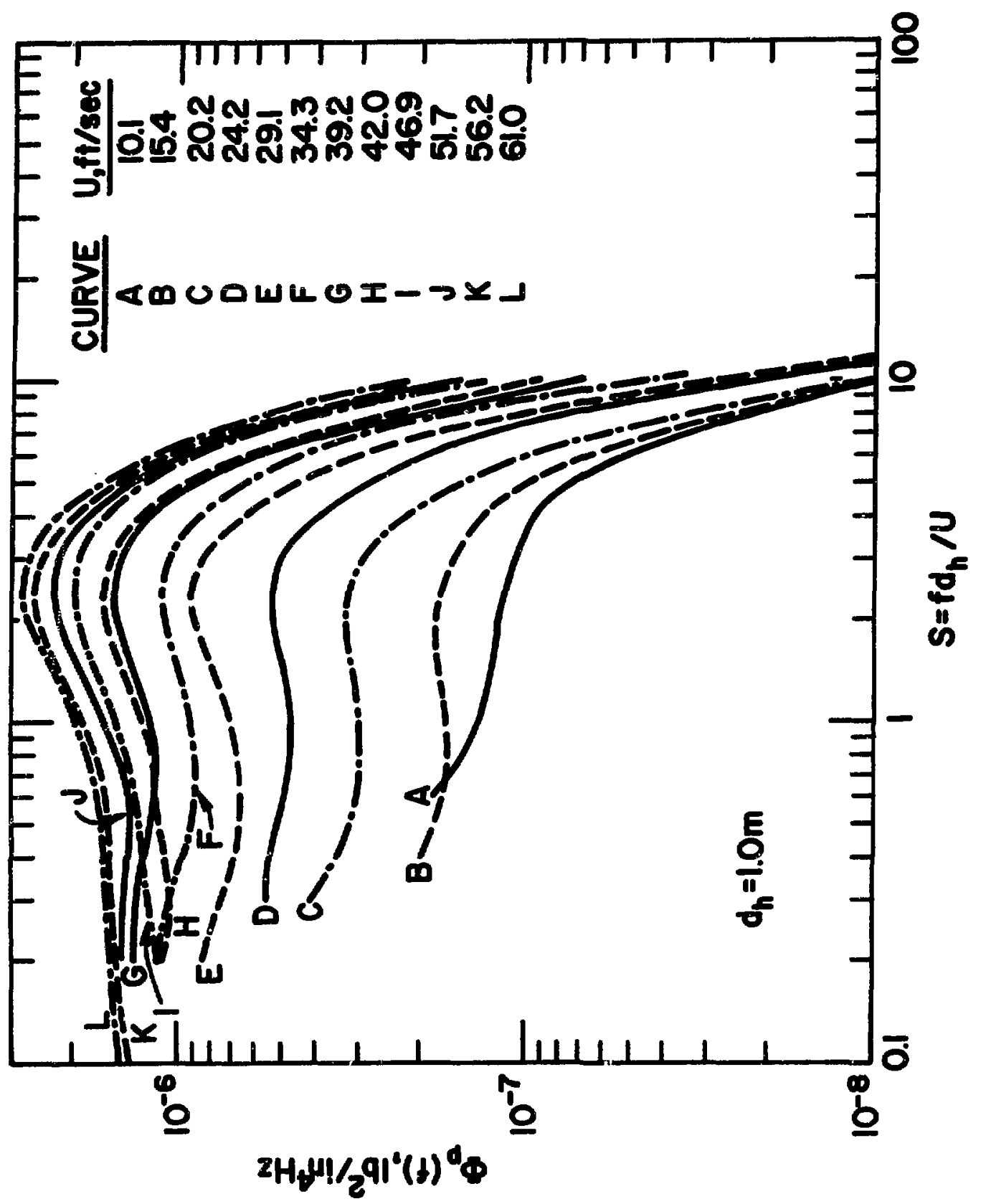

0 
Since the first-mode response is dominant, the cylinder will respond primartly to frequencies in the range of 1 ts $\mathrm{first}$ natural frequency, hence the Strouhal numbers assoclated with this frequency locate their respective range of effectiveness.

From Figs. 3 and 4 observe that in the Strouhal number ranges $(0.01<$ $v<0.6)$ and $(10<\gamma<1000)$, the functions $x(v)$ and $J_{1}^{2}(\gamma)$ can be approximated by straight lines of slopes 0.5 and -1.0 respectively. On $10 g-10 g$ plots, these linear relationships imply the approximate power function relationships

$$
\begin{aligned}
& x(v)=1.3 v^{1 / 2}, 0.01<v<0.6, \\
& \mathrm{~J}_{1}^{2}(\gamma)=0.22 \gamma^{-1}, 10<\gamma<1000 .
\end{aligned}
$$

From BIg. 5 observe that for a given mean axial flow velocity, the near-field spectrum is relatively flat out to a "break frequency." Therefore, In the Strouhal number range $(S<2.5)$ we can write

$$
\Phi(S)=\Phi_{0}(U), S<2.5,
$$

where $\Phi_{0}$ is the intensity, or magnitude, of the near-field mean-square spectrum.

To summarize: Based on these observations, the following approximate relationships can be written which are valid for values of parameters which satisfy the specified ranges,

$$
\begin{array}{ll}
\Phi_{p}(\omega)=\Phi_{0}(U), & \frac{f d_{h}}{U}<2.5, \\
x(\omega)=0.68\left(\omega d / U_{c}\right)^{1 / 2}, & 0.04<\frac{\omega d}{U_{c}}<2.2 ; \\
J_{1}(\omega)=0.47\left(\omega l / U_{c}\right)^{-1 / 2,} & 10<\frac{\omega l}{J_{c}}<1000 ;
\end{array}
$$

On subst1tut1rig Eqs. (11) into Eq. (6), the frequency dependence of the effective dlameter $(x)$ and jolnt acceptance $\left(J_{1}\right)$ cancel, and the mean-square pressure spectral density, being Independent of frequency over the specified range, can be brought outside the Integral. If we let $n=\omega / \omega_{1}$, and further substitute $\mathrm{Eq}$. (3) Into $\mathrm{Eq}$. (6), the resulting equation becomes

$$
\left\langle y^{2}(x, t)\right\rangle=\frac{(0.102) d^{3} \phi_{0}(U) \phi_{1}^{2}(x)}{(L+m)^{2} l \omega_{1}^{3}} \int_{0}^{\infty} \frac{d n}{\left(1-n^{2}\right)^{2}+4 \zeta_{1}^{2} n^{2}} .
$$

The Integral in Eq. (12) can be evaluated as $\pi /\left(4 \zeta_{1}\right)$ by introducing a complex variable and employing the residue theorem; whereupon $\mathrm{Bq}$. (12) becoeses

$$
\left\langle y^{2}(x, t)\right\rangle=\frac{(0.080) d^{3} \phi_{1}^{2}(x)}{(x+m)^{2} l \omega_{1}^{3} \zeta_{1}} \phi_{0}(u) \text {. }
$$


The flowing coolant gives rise to fluid-srructure coupling, resulting in an effertive axial loading which io flow velocity dependent i7]. This contribution to the resultant axial load (additional contributions arise from Initial preload or are caused by diffexential thermal expansion under operating conditions) effects the natural vibration frequency ( $\omega_{1}$ In $\mathrm{Eq} .(13)$ ), and we can write $\omega_{1}=\omega_{1}(U)$. Additionally, effective oystem damping has been shown to be flow-velocity-dependent [12]; consequently, $\zeta_{1}=\zeta_{1}(U)$.

The rms displacement can then be written in the form

$$
y_{\mathrm{rms}}(x, v)=\frac{(0.0180) d^{1.5} \phi_{1}(x) \phi_{0}^{0.5}(v)}{(M+m) l^{0.5} f_{1}^{1.5}(v) \zeta_{1}^{0.5}(v)}
$$

where the frequency $\left(f_{1}\right)$, damping factor $\left(\zeta_{1}\right)$, and intensity of the near-field flow nolse spectrum $\left(\Phi_{0}\right)$ are functions of mean axial flow velocity and are discussed below.

\section{Fundamental Vibration Frequency}

The natural vibration frequency can be obtained from the equation of wotion by neglecting damping effects and asouming a fundamental mode shape. For end conditions which give rise to a symmetric fundamental mode, the fundamental frequency of vibration 18 given by [7]

$$
\omega^{2}=\frac{E I \int_{0}^{l} \phi_{1} \phi_{1}^{I v} d x+\left(M U^{2}-T\right) \int_{0}^{l} \phi_{1} \phi_{1}^{\prime \prime} d x}{(M+m) \int_{0}^{l} \phi_{1}^{2} d x} .
$$

On using the normal modes given by EqB. (4a) and (4b), and performing the indicated integrations, one obtains

$$
\omega_{1}^{2}=\frac{\beta_{0}^{4} \mathrm{EI}}{(M+m) l^{4}}\left[1+\beta_{1}\left(T-M U^{2}\right) \frac{\ell^{2}}{E I}\right],
$$

or

$$
f_{1}^{2}(U)=f_{0}^{2}\left[1-\frac{\beta_{1} M^{2} \ell^{2}}{\left(E I+\beta_{1} T l^{2}\right)}\right]
$$

where $f_{0}$ is the fundamental vibration frequency in static fluid, given by

$$
f_{0}^{2}=\frac{\beta_{0}^{4} E I}{4 \pi^{2}(R+m) l^{4}}\left(1+\beta_{1} \frac{T l^{2}}{E I}\right) \text {. }
$$


For simpl-supported end conditions: $B_{0}=\pi$ and $\beta_{1}=0.101$; and for f1xedfixed end conditions: $\beta_{0}=4.73$ and $\beta_{1}=0.0246$.

\section{Flow-Veloc1ty-Dependent Damping}

The flow-velocity-dependence of system damping assoclated with the vibration of a flexible cylinder subjected to nominally axial flow has been Identifled [1] and studied preliminar1ly [12]. Results show a significant increase In damping factor with increasing mean flow velocity; therefore, this effect should be accounted for In predicting rms displacement response.

Flow-velocity-dependent damping is belng studied In more detail [13]. These studies involve the use of an electromagnetic exciter assembiy, with coils mounted in the wall of the test section, to apply a harmonic force to the cylinder. For selected mean axial flow velocities, forcing frequency is varied and an effective damping factor is computed from measured frequencyresponse curves. Two different measurement methods are used: (1) a modal magnification factor method, with constant force and with constant displacement; and (2) a frequency-bandwidth method.

Figure 6 is a typical plot of measurements made on a $0.5-$ in.-dia, 47-in.-long brass rod with fixed-fixed ends. The data show: (I) the fiowvelocity-dependence of damping; (2) good agreement between the different measurement methods; and (3) good repeatability of measurement (Runs 1 and 2 were performed on different days).

The effects of end restraint, vibration frequency, and Reynolds number are also being Investigated. In general, the data obtained thus far can be fitted with a quadratic equation of the form

$$
\zeta_{1}(v)=\zeta_{0}+a_{1} U+a_{2} U^{2}
$$

where $\zeta_{0}$ is the effective viscous damping factor in stagnant fluid and includes internal damping and external damping associated with friction at the supports, Values of the coefficients $a_{1}$ and $a_{2}$ given on Fig. 6 are typical of those being measured.

\section{B. Flow-Nolse Excitation}

The near-field component of flow nolse, in particular the random pressure fluctuations generated by turbulent eddles, has been Identified as the primary excitation source in the parallel-flow-induced vibration of flexible rods [e.g., Ref. 10]. The resultant convecting random pressure field io characterized via a phenowenological model representing the crose-spectral denstty of the pressure field [8]. This model was used in deriving Eq. (14) for the rmo dioplacement.

A number of Independent atudies of flow nolse in alr and water have been performed in which the men-aquare ppectral denatty of the prenaure field was weasured. In all inotances, the data taken at high frequencies are in good agreenent, but the low-frequency apectra vary widely. In general, It cen be 


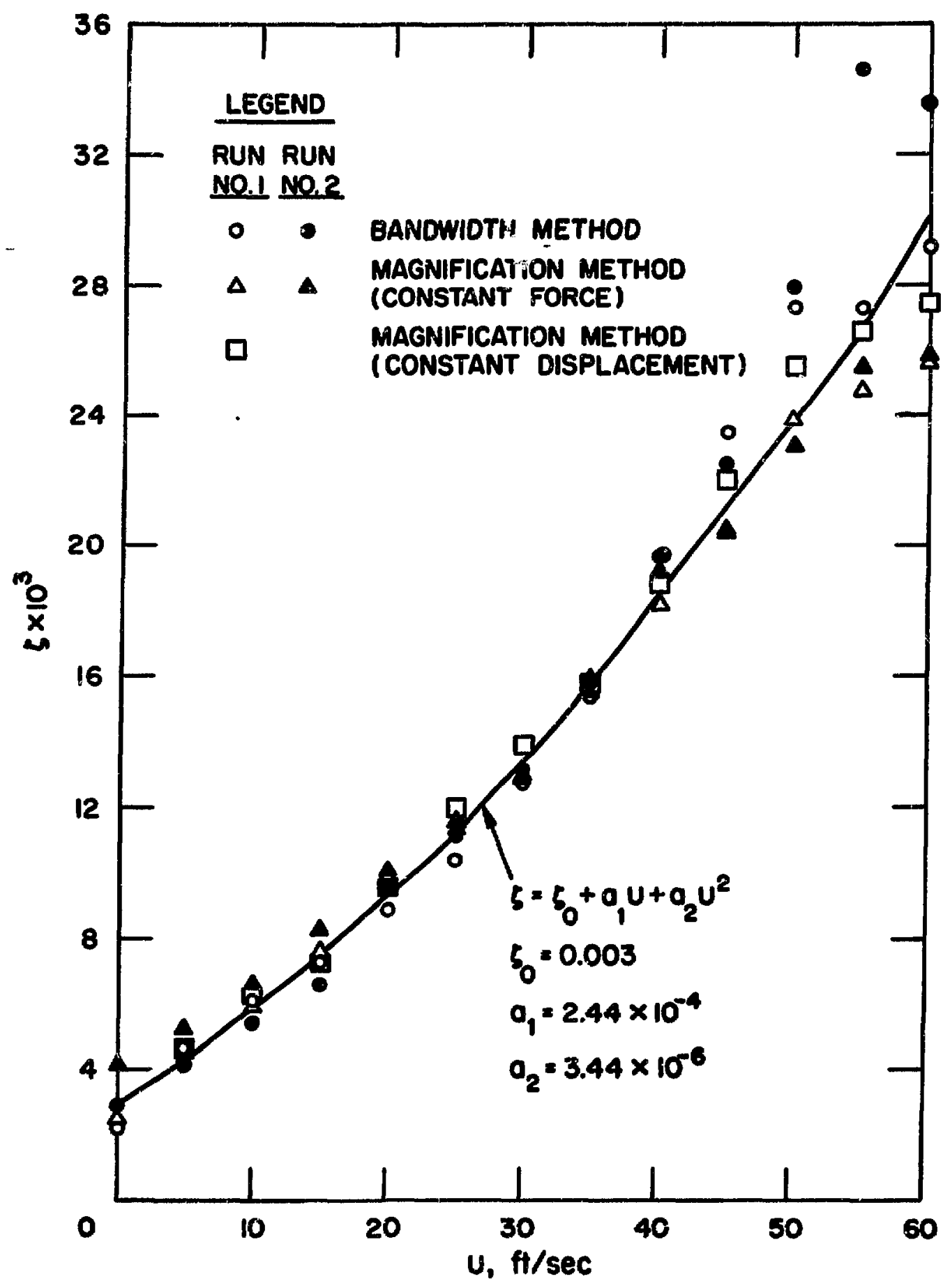

Fig. 6. Equivalont viscous damping factor $\left(\zeta_{1}\right)$ an a function of mean axial how velocity (U) for a 0.5 -in,-dia, 46 f-in.-long brass rod with fixed-fixed ends 
concluded that reliable revulte are not avallable in this frequency range (f $<300 \mathrm{Ex}$ ). However, this is precisely the range of interest for flowInduced votion otudied of many reactor componente (or flexible rods sinulating reactor componenta), alnce it encompesees the range of firot-mode natural freqtencies at which the components predominantly reopond.

The difficulty with measuring the low-frequency behavior of the near-field flow noise is caused priparily by the masking effect of extrancous, low-frequancy acoustic noise. To circunvent this difficulty, a masurement nethod utilizing pairs cf diametrically opposite, minlature, presaure trangducers, flush-mounted on the surface of a rod, wat developed [10]. In oparation, the near-field mean-equare epectra and rmo pressure are conputed" from the preseure-difference algnal, uning the subtraction process to null out the far-field (acoustic) contribution to the flow nolse. Typical results are given In Fig. 5, where the frequency hes been scaled with a strouhal number.

Bquation (14), which describes tas displacement, is based on the assuption that for a given flow velocity the intenulty or wagnitude of the near-field spectum $\Phi_{0}$ is constant out to a Strouhal number $s$ of about 2.5 . From macurements made to date, th1s appears to be a reasonable assumption, although there are some variations as can be seen from Fig. 5 .

It would be desirable to characterize the flow-velocity-dependence of the intenolty of the near-field opectra. However, atteupts at scailng the intensity with a function of wean axial flow velocity have not been entirely succeseful [10]; additional study is required.

The experimental studies of damping at Argonne include - . ourenents of the twe rod displaceant Induced by the flow excltat 1 , and the reconant frequency. Therefore, having experimental values for $f_{1}(U), \zeta_{1}(U)$, and $y_{2=8}(l / 2, U)$, and knowing the dimensions and naterial properties of the rod, Eq. (14) can be solved for $0_{0}(U)$. Preliminary computations show that the intensity is approximately proportional to the man axial flow velocity raiced to the fourth pcrer, and decreases with decraneing hydraulic dianeter. Constdering the small magnitude of the quantities Imolved, and the difficulties in waking the antociated measuremente, the agreciont between computed Intensities and those measured with an Instrumented tast eicaent [10] Is good. This good agrement serves to valldate the model and the derived relationship for sue dieplacement given by $\mathrm{Eg}$. (14).

Based on the preliatiary resulte from the above-mentioned analyols, the intensity of the near-field monn-square spectre in the low-frequency range and on the surface of a "owooth" rod in annular water flow can be charscterised by the enpirical relationohip

$$
\varphi_{0}(v)=x^{2} d_{h}^{3} v^{4}
$$

where

$$
x^{2} \approx 3,16 \times 10^{-10}\left(1 b^{2}\right)\left(2 e c^{5}\right) /\left(1 n .^{4}\right)\left(f t^{7}\right)
$$


Bquation (20) is tertative, since it is based on limited values of $d_{h}\left(0.5<d_{h}\right.$ $<1.5)$ and only one sod dianeter; additional Investigation is planned.

\section{F. Sumary}

Prediction of the rms response of a flexible rod In nominally axial flow requires random-vibration analysis. A one-mode approxiaation to a series solution was ohown to be suffictent, and a representation of the mean-square pectral density of the displacement was obtained utilizing a phenomenological model to characterize the sonvecting random pressure fleld. A parameter study gives rise to approximations which permit evaluation of the integral in the equation for mean-square displacement. A relationship for rms displacement (Bq. (14)) is obtained as a function of natural frequency, damping factor, and the intansity of the near-fleld mean-square spectrum in the low frequency range; these three variables are functions of mean axlal flow velocity.

The flow-velocity-dependence of natural frequency is obtained from analytical considerations, and 18 given by $\mathrm{Eq}$. (17). The natural frequency is also function of axial load, which may vary under operating conditions.

Damping Increases with mean axlal flow velocity. Although the energy dissipation mechanism is not fully understood, a quadratic equation as given by Eq. (19) seems to satisfactorily represent flow-velocity dependence as neasured from experiments.

The flow-velocity-dependence of the intensity of the near-field spectra is the least understood of the three quantities. However, for a smooth rod in annular water flow, $\mathrm{Eq}$. (20) is a reasonable approximation.

Substituting Eqg. (17), (19), and (20) into Eq. (14) glelds the following expression for rms displacement of a flexible rod in annular water flow, with minimal entrance turbulence:

$$
y_{T=B}(x, U)=\frac{(0.0180) K d^{1.5} d_{h}^{1.5} U^{2} \phi_{1}(x)}{e^{0.5} f_{0}^{1.5}(K+m)\left(\zeta_{0}+a_{1} U+a_{2} U^{2}\right)^{0.5}\left[1-\frac{\beta_{1} M U^{2} \ell^{2}}{\left(E I+\beta_{1} T \ell^{2}\right)}\right]^{0.75}}
$$

where

$$
K=2.56 \times 10^{-3}(1 \mathrm{~b})\left(\sec ^{2.5}\right) / \mathrm{Et}^{5.5}
$$

For a aimply-supported rod

$$
B_{1}=0.101, \phi_{1}(x)=\sqrt{2} \sin (\pi x / \ell), 0<x<\ell ;
$$

and for a fixed-fixed rod

$B_{1}=0.0246$ 


$$
\begin{aligned}
\phi_{1}(x)= & \cosh (4.73 x / \ell)-\cos (4.73 x / \ell)-0.983[\sinh (4.73 x / \ell) \\
& -\sin (4.73 x / \ell)], 0<x<\ell .
\end{aligned}
$$

In application, it is necessary:

(1) To assume or measure the damping factor $\left(\zeta_{0}\right)$ in stagnant fluid.

(2) To assume values for $a_{1}$ and $a_{2}$ based on Independent studies of damping $\left(a_{1}=2.4 \times 10^{-4}\right.$ sec/ft, and $a_{2}=3.4 \times 10^{-6} \mathrm{sec}^{2} / \mathrm{ft}^{2}$ are typical values). If they were to be measured, cne might just as easily measure $y_{\mathrm{rms}}$.

(3) To assume a value for the axial load $T$, or to calculate it from Eq. (18), using a measured value of natural frequency in static fluid. .

The remaining quantities are known from the system geometry and the material properties of the rod.

Amplitudes are of primary importance, ofnce the mode of failure most likely will be fretting or wear. However, for those cases in which stresses are of concern, they are sasily obtained from displacements, is given by

$$
\left[\sigma_{y}(x, v)\right]_{I m B}=\frac{E d}{2} \frac{\partial^{2} y_{I m s}(x, U)}{\partial x^{2}}
$$

or, In terms of midpoint displarement as given by

$$
\left[\sigma_{y}(x, U)\right]_{\operatorname{rms}}=\left[\frac{E d \phi_{1}^{\prime \prime}(x)}{2 \phi_{1}(l / 2)} y_{\mathrm{rms}}(x / 2, u),\right.
$$

where a prime (') denotes differentiation with respect to $x$. Values for the mode shape $\phi_{1}$, and Its second cierivative $\phi_{1}^{\prime \prime}$, are tabulated in Ref. 14.

\section{ARPLITUDE DISTRIBUTION}

Absolute values of amplitude are meaningless because we are dealing with a random vibration phenomenon. Therefore, we have developed a relationshtp to predict the rms displacement response. Although this Information is useful, a complete description of the random signal requires knowledge of the probability law deacribing the amplitude distribution. For example, two random motions can have the same rms displacement, but one could experience peak mplitudes eignificantly greater than the other and/or more frequently pex given enmple length.

Displacement-time histories from number of different flow tests have been processed on an amplitude-distribution anulyzer. The shapes of the curves obtained suggeet notmal or Gusgian distribution. Ao shown In Fig. 7 . which 18 a typical probability density representation of vibration amplitude, the nornal probability law approximates the data quite well. 


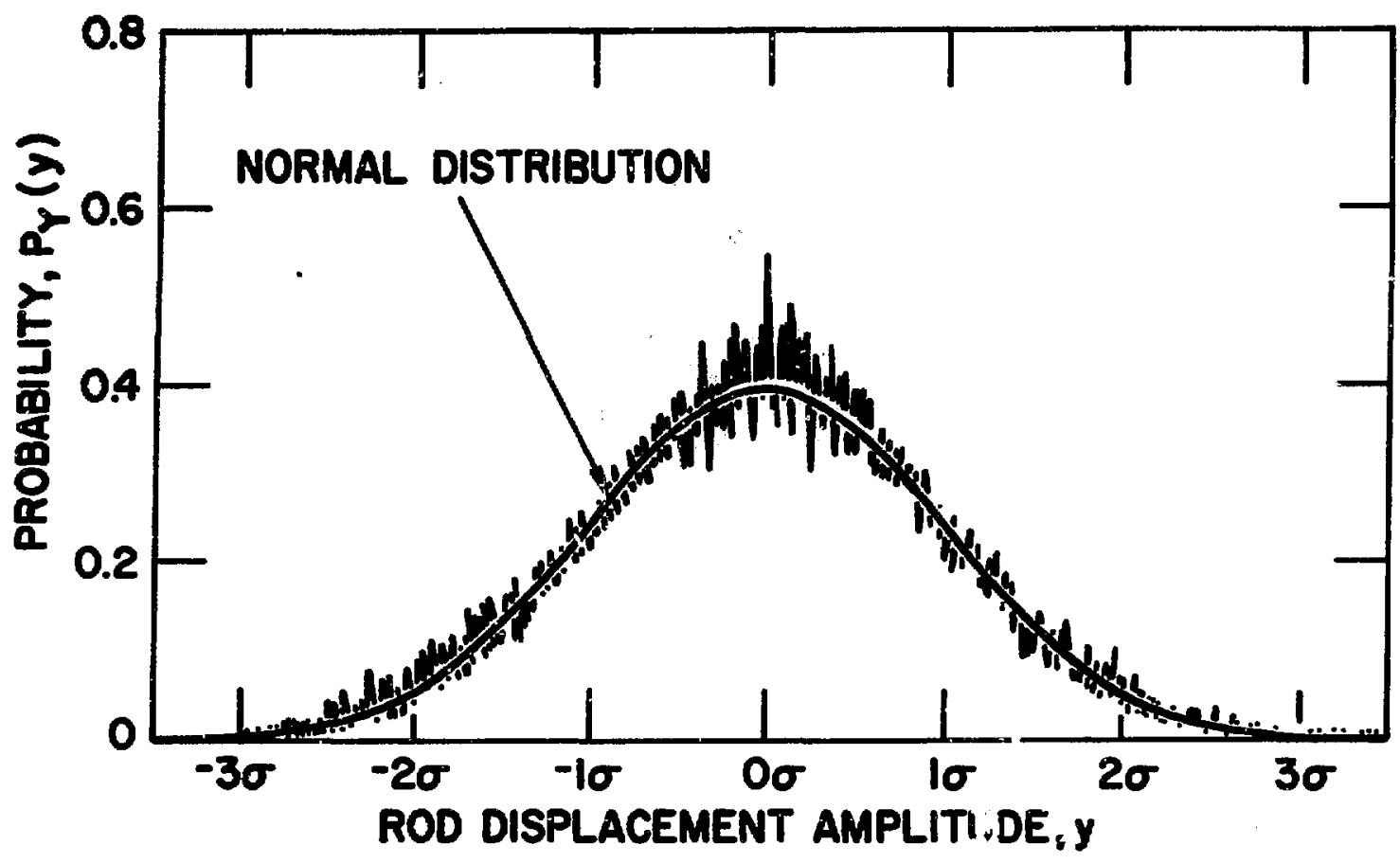

Fig. 7. Typical probability-density representation of displacement of flexible cylinder vibrating in parallel-flowing fluid ( $\sigma=\mathrm{rms}$ value $=2.34 \mathrm{mils} ; U=16 \mathrm{ft} / \mathrm{sec}$ ) 
Based on this agreement, we can assume a normal distribution for the diatribution of vibration amplitude in a given direction, and write the probability law as

$$
p_{Y}(y)=\frac{1}{\sqrt{2 \pi} \sigma} \exp \left[-\frac{1}{2}\left(\frac{y}{\sigma}\right)^{2}\right] \text {. }
$$

which implies a mean value of zero ( $\sigma$ is the standard dcviation, and for a zero mean value is equal to the rms value). The probability that an observed. value of displacement will range between $-y_{0}$ and $y_{0}$ is determined by the Integration

$$
P\left[-y_{0} \leq y \leq y_{0}\right]=\int_{-y_{0}}^{y_{0}} P_{Y}(y) d y=\frac{1}{\sqrt{2 \pi} \sigma} \int_{-y_{0}}^{y_{0}} \exp \left[-\frac{1}{2}\left(\frac{y}{\sigma}\right)^{2-} d y .\right.
$$

The normal probability Integral has been evaluated and is tabulated in vartous sources [e.g., Ref. 15]. Several values are listed below:

\begin{tabular}{cc}
$\frac{n}{0.5}$ & $P[-n \leq y \leq n]$ \\
1.0 & 0.383 \\
1.5 & 0.683 \\
2.0 & 0.866 \\
2.5 & 0.954 \\
3.0 & 0.988 \\
\hline
\end{tabular}

Observe the probability of 0.997 that the absolute vibration amplitude will be less than $3 \sigma ;$ that $18,99.7 \%$ of the time the amplitude can be expected to be less than $3 \sigma$, or $3 y_{\text {rms }}$. Such Information is useful in fatigue and wear studies and in determining if impacting with adjacent components or support members may occur.

\section{EXAMPLE OF APPLICATION}

Consider the case of a long, slender tube concentrically located within a containment tube and subjected to coolant flow; system dimensions and materlal properties are given in Table $I$. The end conditionis can be approximated as fixed, and axial loading will be asbumed negligible. The problem: Find the flow-Induced, zms displacement of the midpoint of the tube. 
TABLE I

\section{Data for Sample Problem}

Tube

Outside Diameter (d)

0.4 In.

Inside Diameter $\left(d_{1}\right)$

$0.3 \mathrm{in}$.

Length (l)

96 In.

Material: atalnless steel

Dersity ( $p$ )

$15.6(1 \mathrm{~b})\left(\mathrm{sec}^{2}\right) / \mathrm{ft} \mathrm{t}^{4}$

Young 's Modulus

(E)

$28 \times 10^{6} 1 \mathrm{~b} / \mathrm{in.}{ }^{2}$

Contaiment Tube

Inside Diameter (D)

1.5 in.

Coolant

Water

Density $\left(p_{f}\right)$

$1.94(1 b)\left(\sec ^{2}\right) / f t^{4}$

Velocity (U)

$40 \mathrm{ft} / \mathrm{sec}$

The following calculational steps are required:

(1) Hydraulic diameter $\left(d_{h}\right)$

$$
\begin{aligned}
& d_{h}=\frac{4 \text { (Flow Area) }}{\text { (Wetted Perimeter) }} \\
& d_{h}=\frac{4 \pi\left(D^{2}-d^{2}\right)}{4 \pi(D+d)}=D-d \\
& d_{h}=0.0917 \mathrm{ft}
\end{aligned}
$$

(2) Mass per unft length of tube (m)

$$
\begin{aligned}
& m=\rho\left[\pi\left(d^{2}-d_{1}^{2}\right) / 4\right] \\
& m=5.96 \times 10^{-3}(1 b)\left(\sec ^{2}\right) / f t^{2}
\end{aligned}
$$

(3) Added mass per unit length of fluid (u)

From Eq. (5)

$$
H=c_{m} \rho_{f}\left(\pi d^{2} / 4\right)
$$

For $D / d=3.75$, we read $C_{m}=1.15$ froc Fis. 2 and obtain

$$
M=1.95 \times 10^{-3}(1 \mathrm{~b})\left(\sec ^{2}\right) / \mathrm{ft}^{2}
$$


(4) Homent of inertia (I)

$$
\begin{aligned}
& I=\pi\left(d^{4}-d_{1}^{4}\right) / 54 \\
& I=4.14 \times 10^{-8} \mathrm{ft}^{4}
\end{aligned}
$$

(5) Natural vibration frequency in stagnant fluid $\left(f_{0}\right)$

From Eq. (18), with no axial preload $(T=0)$,

$$
f_{0}=\frac{B_{0}^{2}}{2 \pi \ell^{2}}\left[\frac{E I}{(M+m)}\right]^{1 / 2} \text {. }
$$

For fixed-fixed end conditions $B_{0}=4.73$ and

$$
f_{0}=8.1 \mathrm{~Hz}
$$

The next step 18 to compute the Strouhal numbers $f_{o} d_{h} / U, \omega_{o} d / U_{c}$, and $\omega_{o} l / U_{c}$, and verify that the values fall within the ranges opecified in Eqs. (11), for which the analysis is valid. From the above computations,

$$
\omega_{0}=2 \pi f_{0}=50.9 \mathrm{rad} / \mathrm{sec} \text {; }
$$

$v_{c}$ is the convection velocity of the pressure field and is approximately $0.8 \mathrm{v}$; therefore,

$$
u_{c}=0.8 v=32 \mathrm{ft} / \mathrm{sec}
$$

The Strouhal numbers are

$$
\begin{aligned}
& f_{o} d_{h} / U=0.019 \\
& \omega_{0} d / U_{c}=0.053 .
\end{aligned}
$$

and

$$
\omega_{0} \ell / y_{c}=12.7
$$

From Eqs. (11) we see that the values lie within the range over which the approximation is valid.

Por dIsplacement at the midpoint, $x=\ell / 2$, and $\phi_{1}(\ell / 2)=1.588$, as obtained from Eq. (4a) or Ref. 14. Let us assume: (1) the effective viscous damping factor in stagnant fluid $r_{0}$ is 0.008 ; and (2) the flow-velocitydependence of damping 18 that BIven in Fig. 6; therefore $a_{3}=2.44 \times 10^{-4} \mathrm{sec} / \mathrm{ft}$, and $\mathrm{a}_{2}=3.44 \times 10^{-6} \mathrm{eec}^{2} / \mathrm{ft}^{2}$. Substituting these values into $\mathrm{Eq}$. (21), we compute

$$
y_{\text {rms }}=3.1 \mathrm{mils}
$$

as the expected flow-induced, rms displacement of the tube for a coolant flow velocity of $40 \mathrm{ft} / \mathrm{sec}$. 


\section{v. DISCUSSION}

Equation (i4), which describes the rms displacement response, is derived from a theoretical analysis using the results of a parimeter study to aimplify the solution. It is applicable in the design evaluation of many reactor system components which are subjected to nominally axial coolant flow, specifically those with parameters satisfying the Strouhal number ranges specified in Eq. (11). It is also applicable to pipes conveying fluid.

The primary difficulty assoclated with direct usage of Eq. (14) is that the system and flow-velocity dependence of the intensity of the near-field nean-square spectra in the low-frequency range of interest 18 not known. Therefore, since near-field flow noise is strongly system dependent, accurate prediction of displacentent requires measurement of the pressure field in a prototypic assembly closely simulating the geometry and flow paths of the real aystem. However, the pressure measurements are difficult to perform; moreover, if a prototypic assembly was avallable, one might as we11. measure displacement response directly.

Equation (21) is an empirical relationship for ms displacement derived from Eq. (14) and based on experiments Involving a smooth, flexible cyliader in annular water flow. It 18 in terms of known quantitles and 1s, therefore, easily used by designers. However, since it is based on results from a smooth cylinder In flow with minimal entrance effects, the computed rms response represents a lower bound on the actual displacement. It is the response the designer can expect in a systen designed for minimum turbulence by streamilning flow paths and providiag isolation from external, structural-borne vibrations. The upper bound w11l depend on the system.

In addition to providing Insight fnto the resporse problem and a "feel" for the magnitude of the displacement induced by near-field flow nolse, the results can be useful in design evaluation. For example, if the response computed from Eq. (21) exceeds the allowable response determined from consideratlons of damage and fallure mechanisms, the designer will know immediately that his design must be revised. 
REFERENCES

1. Wambsgans8, M. H., and Boers, B. L., Parallel-Elow-Induced Vibration of a Cyindrical Rod, ASKE Paper No. 68-WA/HE-15 (Necember 1968).

2. Paidoussis, M. P., Vibration of Flexible Cylinders with Supported Ends, Incuced by Arial Flow, Proc. Inst. Mech. Engrs. 180 (Pt. 3J), 268-278 (19651966).

3. Basile, D., Faure, J., and Ohlmer, E., Experimental study on the Vibration of Various Fuel Rod Models in Parallei Flow, Nucl. Ens. Design I, 517-534 (1968).

4. Paidoussis, M. P.. An Experimental Study of Vibration of Elexible Cylinders Induced by Nominaily Axial Flow, Nuc1. Sc1. Eng. 35, 127-138 (1969).

5. Reavis, J. R., Vibration Correlation for Maximum Fuel-Element Displacement in Paraizez Turbulent Flow, Nuc1. Sci. Eng. 38, 63-69 (1969).

6. Paldoussis, M. P., Dynanics of Flexible Slender Cylinders in Axial Flow, Part I: Theory, J. Fluld Mech. 26 (Pt. 4), 717-736 (1966).

7. Chen, S. S., and Wambsganss, M. W., Response of a Flexible Rod to Nean-Field Flow Noise, Proc. Conf, on Flow-Induced Vibrations in Reactor System Components, Argonne National Laboratory, May 14 and 15, 1970, ANL-7685, pp. 5-31.

8. Corcos, G. M., Resolution of Pressure in Turbulence, I. Acoust. Soc. Am. 35, 192-199 (1963).

9. Chen, S. S., and Hambsganss, M. H., Parallel-Flow-Induced Vibration of Fuel Rods, Paper to be presented at the 1st Int. Conf. on Structural Mechanics in Reactor Technology, Berlin, Germany, Sept. 20-24, 1971.

10. Wambsganss, M. W., and Zalesk1, P. L., Measurement, Interpretation and Characterization of llearfield Flow Noise, Proc. Conf. on Flow-Induced Vibrations in Reactor System Components, Argonne National Laboratory, May 14-15, 1970. ANL-7685, Pp. 112-140.

11. Wambsganse, M. W., Near-field and Eam-field Noibe, Reactor Development Program Progreas Report for July 1970, ANL-7726 (August 1970), pp. 134-136.

12. Wambsgansв, M. W., and Zalesk1, P. L., Elow-VeZocity-Dependerce of Damping in Parailel-Fiow-Induced Vibration, Trans. Am. Nucl. Soc. 12(2), 839-840 (1969).

13. Wambsgans8, M. W., Danping and Virtual Nass, Reactor Deve Zopment Program Progress Report for January 1971, ANL-7776 (February 1971), PP. 86-88.

14. Bishop, R. E. D., and Johnson, D. C., Vibration Analyeis Tables, Cambridge University Press, Cambridge, 1956.

15. Dwight, H. B., Tables of Integrals and other Mathematioal Data, 3rd s. Macmillan Company, New York, 1957. Table 104k, P. 275. 